\title{
Immunohistochemical analysis of CDw52 antigen expression in non-Hodgkin's lymphomas
}

\author{
J R Salisbury, N T Rapson, J D Codd, M V Rogers, A B W Nethersell
}

\begin{abstract}
Aim-To determine the antigen expression of CDw52 using Campath-1 antibodies in a series of non-Hodgkin's lymphomas (NHLs).

Methods-Tissue sections of lymphoma were stained immunohistochemically using rat Campath-1G and humanised Campath-1H with avidin-biotin-peroxidase complex techniques. Fifty-two fresh frozen lymphomas and a further 26 paraffin wax embedded sections were studied.

Results-Thirty-seven out of 41 B cell lymphomas were positive with Campath$1 \mathrm{H}$ in frozen sections (low grade, 24 of 24; high grade, 13 of 17) as were three out of five $T$ cell lymphomas. Reed-Sternberg cells in six cases of Hodgkin's disease did not react. Eleven out of 16 high grade B cell lymphomas also stained positively with Campath-1G in paraffin wax sections as did five out of $10 \mathrm{~T}$ cell lymphomas.

Conclusions-The Campath-1 antibodies showed that CDw52 antigen expression was present in all cases of low grade B cell NHL examined. Immunohistochemical staining in high grade $B$ cell NHL and in T cell NHL was variable. These findings may be relevant to patient selection when considering treatment with Campath-1 antibodies.
\end{abstract}

(f Clin Pathol 1994;47:313-317)

The Campath-1 series of rat monoclonal antibodies were produced by Waldmann et al for lysis of normal and malignant lymphoid cells. ${ }^{1}$ The antibodies recognise the CDw52 antigen, ${ }^{2}$ a small glycoprotein linked to the surface membrane by a glycosylphosphatidylinositol (GPI) anchor. ${ }^{34}$ The antigen is present on the cell membrane of lymphocytes and monocytes/macrophages and in seminal fluid, ${ }^{5}$ but is absent from granulocytes, platelets, red cells, and bone marrow stem cells. ${ }^{1}$ The first antibody in the series to be used clinically was an IgM, Campath-1M, which was selected for its highly efficient lysis of target cells using complement. It was used to purge marrow ex vivo in allogeneic bone marrow transplantation, where it decreased the incidence of graft verus host disease. ${ }^{6}$ When used in vivo in patients with lymphoid malignancies, Campath-1M transiently reduced peripheral blood cell numbers but did not affect marrow, spleen, or nodes. ${ }^{7}$ A similar result was obtained with an $\mathrm{IgG}_{2 \mathrm{a}}$ antibody against $\mathrm{CDw} 52$, derived from the same fusion experiment, which also mediated cell lysis with complement. Subsequently, an $\operatorname{IgG}_{2 b}$ class-switch variant, (Campath-1G), ${ }^{8}$ derived from the $\mathrm{IgG}_{2 \mathrm{a}}$ clone was much more effective. ${ }^{7}$ Campath-1G was used to treat patients with a variety of leukaemias and non-Hodgkin's lymphomas, some of whom underwent remission. ${ }^{8}$ This increased efficacy was ascribed to the ability of Campath-1G to kill target cells by antibody dependent cellular cytotoxicity (ADCC), which was not mediated by other isotypes. ${ }^{9}$ However, repeated treatment of some patients was precluded by development of an antirodent globulin response. ${ }^{9}$ To avoid this, and to optimise the interaction of the antibody with human effector cells, Campath-1G was "humanised" by grafting the complementary determining regions from the rat antibody variable region into the human $\operatorname{IgG}_{1}$ framework. ${ }^{10}$ The resulting monoclonal antibody, designated Campath-1H, was expressed in rat YO myeloma cells and used to induce remission in two patients with non-Hodgkin's lymphoma (NHL). ${ }^{11}$ Campath-1H was later expressed in Chinese hamster ovary (CHO) cells, ${ }^{12}$ to facilitate large scale production.

\section{Methods}

CELL CULTURE AND PURIFICATION OF ANTIBODIES

Campath-1H was purified from the supernatant fluid of the $\mathrm{CHO}$ cell line grown in serum free medium. The rat hybridoma secreting Campath-1G and a human/mouse heteromyeloma, TT46, secreting a human $\mathrm{IgG}_{1}$ anti-tetanus monoclonal antibody used as a negative control, were grown in RPMI medium with $5 \%$ fetal bovine serum. The antibodies were purified using Protein A Sepharose, S-Sepharose, and Superdex 200 columns.

PREPARATION OF $\mathrm{F}(\mathrm{ab})_{2}$ FRAGMENTS $\mathrm{F}(\mathrm{ab})_{2}$ fragments were prepared from Campath-1H and TT46 IgG by addition of $5 \mu \mathrm{g}$ pepsin (Sigma) per mg IgG in $0.1 \mathrm{M}$ citrate (pH 3.5). After incubation at $37^{\circ} \mathrm{C}$ for three hours the fragments were purified on a Superdex 200 column. Purity of the fragments was confirmed by non-reducing sodium dodecyl sulphate polyacrylamide gel electrophoresis (SDS PAGE). 
BIOTIN LABELLING

Campath-1H and TT46 antibody were biotinylated on accessible amino groups with D-biotinyl-E-amidocaproic acid N-hydroxy succinimide ester (NHS-biotin, Pierce) using either of the following methods: (1) Campath$1 \mathrm{H}$ and TT46 were labelled according to the method of Cobbold et al. ${ }^{13}$ Briefly, $25 \mathrm{mg}$ of purified antibody in $1 \mathrm{ml}$ of distilled deionised water (DDW) was dialysed against $0.1 \mathrm{M}$ sodium bicarbonate buffer $(\mathrm{pH} 9.3)$ for
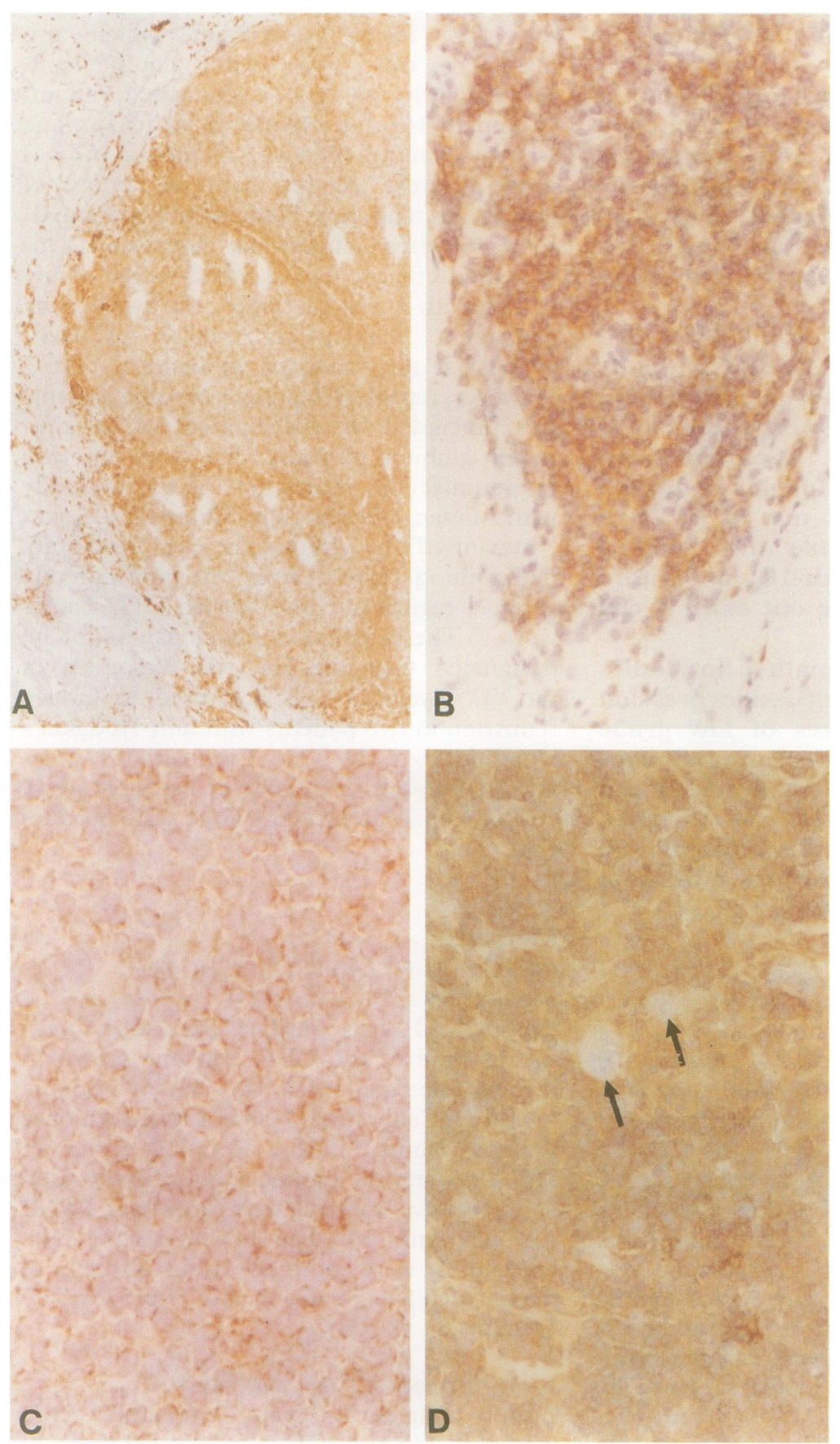

Figure 1 Cryostat sections stained with biotinylated Campath-1H. (A) Low power view of non-neoplastic human tonsil showing lymphoid follicles, with germinal centres composed of follicle centre cells, and the intervening paracortical tissues are all stained. (B) Medium power view of non-neoplastic human tonsil showing staining of small lymphocytes. Surrounding connective tissue and small vessels are unstained. (C) Centroblasticl centrocytic lymphoma, follicular, showing membrane staining. (D) Mixed cellularity Hodgkin's disease. The reactive $T$ cells are stained. Reed-Sternberg cells (arrows) and small vessels are unstained. Avidin-biotin complex immunoperoxidase technique with haematoxylin counterstain was used for all sections.
16 hours at $4^{\circ} \mathrm{C}$. NHS-biotin $(120 \mu \mathrm{g})$ solubilised in dimethyl formamide to $50 \mathrm{mg} / \mathrm{ml}$ was added per $\mathrm{mg}$ of antibody and incubated at room temperature. The labelled antibody was then dialysed against phosphate buffered saline (PBS) (pH 7.2) for 16 hours and, after adjusting the protein concentration to $5 \mathrm{mg} / \mathrm{ml}$, stored as aliquots at $4^{\circ} \mathrm{C}$. (2) A second method, which gives a higher degree of biotinylation, was performed as follows. Campath-1 $\mathrm{H}(1.2 \mathrm{mg} / \mathrm{ml})$ was dialysed into DDW which had been carefully adjusted to pH 10 with $1 \mathrm{M} \mathrm{NaOH}$. NHS-biotin $(208 \mu \mathrm{g})$ was added per mg of antibody and then incubated at room temperature for 4 hours. The antibody was then dialysed against PBS as described above.

\section{FLUORESCEIN LABELLING}

Campath-1H IgG, Campath-1H $\mathrm{F}(\mathrm{ab})_{2}$ fragments, and TT46 IgG were dialysed against $0 \cdot 25 \mathrm{M}$ carbonate/bicarbonate buffer (pH 9.0). Fluorescein isothiocyanate (Sigma) $(50 \mu \mathrm{g})$, from a $1 \mathrm{mg} / \mathrm{ml}$ stock in the same buffer, was added per mg of antibody and incubated at $4^{\circ} \mathrm{C}$ for 16 hours. The conjugates were separated on Sephadex G25 columns equilibrated in PBS. The protein concentrations and fluorescein:protein ratios of the final preparations, determined by measuring the optimal density at $280 \mathrm{~nm}$ and $495 \mathrm{~nm}$, were FITC-Campath-1H, $4.7 \mathrm{mg} / \mathrm{ml}$ and $5 \cdot 39: 1 ;$ FITC-F $(\mathrm{ab})_{2}$ Campath-1H, $0.8 \mathrm{mg} / \mathrm{ml}$ and $2 \cdot 7: 1$; FITC-TT46 3.35 $\mathrm{mg} / \mathrm{ml}$ and $2 \cdot 97: 1$.

\section{TISSUES}

Samples of fresh tissue from 41 B cell nonHodgkin's lymphomas (NHLs), five $T$ cell NHLs, and six cases of Hodgkin's disease (three nodular sclerosis, three mixed cellularity), all removed as surgical specimens at King's College Hospital, were snap frozen and stored in liquid nitrogen. The remainder of the tissue was fixed in formalin and embedded in paraffin wax for light microscopic examination. All lymphomas were diagnosed by standard histological criteria and NHLs classified according to the updated Kiel classification. ${ }^{14}$ Paraffin wax section immunohistochemistry was used to confirm NHL positivity for CD45 (leucocyte common antigen) and to immunophenotype,,$^{15}$ as to $B$ or $\mathrm{T}$ cell lineage, with a small panel of antibodies (CD20 (L26, Dako), CD43 (MT1, Euro-Diagnostics), CD45RA (MB1, Euro-Diagnostics) and CD45R0 (UCHL1, Dako))..$^{17-19}$ For Campath-1 staining, cryostat sections ( $4 \mu \mathrm{m}$ thick) were cut from the frozen tissue blocks and fixed in acetone for $10 \mathrm{~min}$ utes. Serial sections were cut and stained with haematoxylin and eosin to monitor tissue quality.

Formalin fixed, paraffin wax-embedded blocks from a further 26 cases of high grade B cell and T cell NHL were obtained from the surgical files of the Department of Histopathology, King's College School of Medicine and the Department of Histopathology, St Bartholomew's Hospital 
Medical College. Sections ( $4 \mu \mathrm{m}$ thick) were cut and utilised for Campath-1 staining.

A relatively large proportion of high grade NHL cases were selected for inclusion in the study. The number of cases within each diagnostic subtype in this study does not reflect their proportions in our ordinary diagnostic caseload.

\section{IMMUNOHISTOCHEMICAL STAINING}

Several different tissue staining methods were investigated in an attempt to optimise the evaluation of CDw52 expression in normal lymphoid and lymphoma tissues. These included the use of biotinylated Campath-1 $\mathrm{H}$ for both cryostat and paraffin wax sections, and FITC-labelled Campath-1H, FITClabelled Campath-1H F(ab) ${ }_{2}$, and myelomaderived Campath-1G for paraffin wax sections. Antibody dilution titres and trypsin times were optimised on cryostat or paraffin wax sections of non-neoplastic human palatine tonsils as appropriate.

On cryostat sections, Campath-1H-biotin conjugate was used at a dilution of 1 in 5 in a two-layer avidin-biotin-peroxidase complex (ABC) technique. ${ }^{20}$ After washing, peroxidase activity was shown by incubation in a fresh solution of 3',3'-diamino-benzidine tetrahydrochloride (Sigma) in TRIS-HCl-buffer ( $\mathrm{pH}$ 7.6) with $\mathrm{H}_{2} \mathrm{O}_{2}$. Sections were then lightly counterstained with haematoxylin. Biotinconjugated human IgG $_{1}$ anti-tetanus toxin (TT46) was used as a negative control.

Biotinylated Campath-1 $\mathrm{H}$ was applied to paraffin wax sections, in a range of dilutions from 1 in 10 to 1 in 1000, as the first step in a two-layer avidin-biotin complex technique following pre-treatment of the sections with trypsin. Trypsin digestion times of between 5 and 20 minutes were examined.

FITC-Campath-1H was used at dilutions of 1 in 100 to 1 in 800 on paraffin wax sections of human tonsil. FITC-TT46 was used as the negative control. FITC-Campath-1H $\mathrm{F}(\mathrm{ab})_{2}$, diluted 1 in 100 to 1 in 1000 , was utilised in a direct immunofluorescence technique on paraffin wax sections of formalin fixed human tonsil.

Table 1 Immunohistochemical staining of cryostat sections with biotinylated Campath-1H by non-Hodgkin's lymphoma subtype

\begin{tabular}{|c|c|c|c|c|}
\hline \multirow[b]{2}{*}{ Histology } & \multicolumn{4}{|c|}{ Campath-1H staining } \\
\hline & No of cases & + & \pm & - \\
\hline \multicolumn{5}{|l|}{$B$ cell lineage: } \\
\hline Lymphocytic & 1 & 1 & 0 & 0 \\
\hline Lymphoplasmacytoid/cytic & 4 & 4 & 0 & 0 \\
\hline Centroblastic/centrocytic follicular & 15 & 15 & 0 & 0 \\
\hline Centroblastic/centrocytic diffuse & 1 & 1 & 0 & 0 \\
\hline Centrocytic & 2 & 2 & 0 & 0 \\
\hline Cutaneous B cell lymphoma & 1 & 1 & 0 & 0 \\
\hline \multicolumn{5}{|l|}{ High grade } \\
\hline Centroblastic & 5 & 5 & 0 & 0 \\
\hline Immunoblastic & 3 & 2 & 1 & 0 \\
\hline Large cell anaplastic & 7 & 4 & 1 & 2 \\
\hline Unclassifiable & 2 & 2 & 0 & 0 \\
\hline \multicolumn{5}{|l|}{ T cell lineage: } \\
\hline Mycosis fungoides & 2 & 1 & 0 & 1 \\
\hline Adult T leukaemia/lymphoma (HTLV1 + ) & 1 & 1 & 0 & 0 \\
\hline $\mathrm{T}$ cell immunoblastic & 1 & 0 & 0 & 1 \\
\hline High grade unclassifiable & 1 & 1 & 0 & 0 \\
\hline
\end{tabular}

Campath-1G rat monoclonal antibody was used for cryostat and paraffin wax sections at a dilution of 1 in 1000 in a three-layer avidinbiotin complex technique with biotin-conjugated rabbit anti-rat immunoglobulins as the second stage, followed by avidin-biotin complex. Pretreatment of paraffin wax sections by trypsin digestion was necessary. Trypsin digestion times of between 5 and 20 minutes were considered and 10 minutes selected as optimal. The primary antibody was incubated overnight at $4^{\circ} \mathrm{C}$. Peroxidase activity was demonstrated as above. Negative controls were obtained by substituting TRIS buffer for the primary antibody.

\section{Results}

Biotinylated Campath-1H applied to cryostat sections of non-neoplastic human tonsils showed strong membrane staining of small lymphocytes in both $B$ cell and $T$ cell areas and weaker staining of follicle centre cells (figs $1 \mathrm{~A}$ and $\mathrm{B})$. There was no staining of plasma cells, fibrous connective tissue, blood vessels, myelinated nerves or striated muscle or of viable squamous epithelium (although the non-viable keratin squames did show considerable non-specific staining). The amount of biotinylation of the Campath- $1 \mathrm{H}$ was critical as staining was abolished at the higher degree of biotinylation. The biotin-conjugated antitetanus toxin treated sections did not stain.

Of the 41 B cell malignant lymphomas tested with Campath-1H, 37 were positive, showing membrane staining, two cases showed very faint staining, and two cases did not stain (table 1). These four cases were all high grade B cell lymphomas, either large cell anaplastic or B cell immunoblastic subtype. All cases of low grade B cell lymphoma stained positively (fig $1 \mathrm{C}$ ).

Three out of the five T cell malignant lymphomas tested were positive (table 1). The two negative $T$ cell lymphomas were examples of mycosis fungoides and $\mathrm{T}$ cell immunoblastic subtype.

Cryostat sections of the six cases of Hodgkin's disease (three nodular sclerosis, three mixed cellularity), stained with biotinylated Campath-1H, showed that ReedSternberg cells and mononuclear Hodgkin's cells did not stain (fig 1D). The surrounding lymphocytes acted as internal positive controls.

Reliable or consistent staining could not be obtained with biotinylated Campath-1H in paraffin wax sections, either with or without enzymatic pre-digestion. FITC-Campath-1H and FITC-Campath-1H $\mathrm{F}(\mathrm{ab})_{2}$ also did not stain paraffin wax sections.

Campath-1G staining on paraffin wax sections of non-neoplastic human lymphoid tissue (tonsils) showed strong membrane staining on small lymphocytes in the mantle zones and paracortex. Weaker membrane staining was seen in follicle centre cells. Plasma cells were negative. Therefore, the Campath-1G staining of lymphoid cells in paraffin wax sections seemed equivalent to 

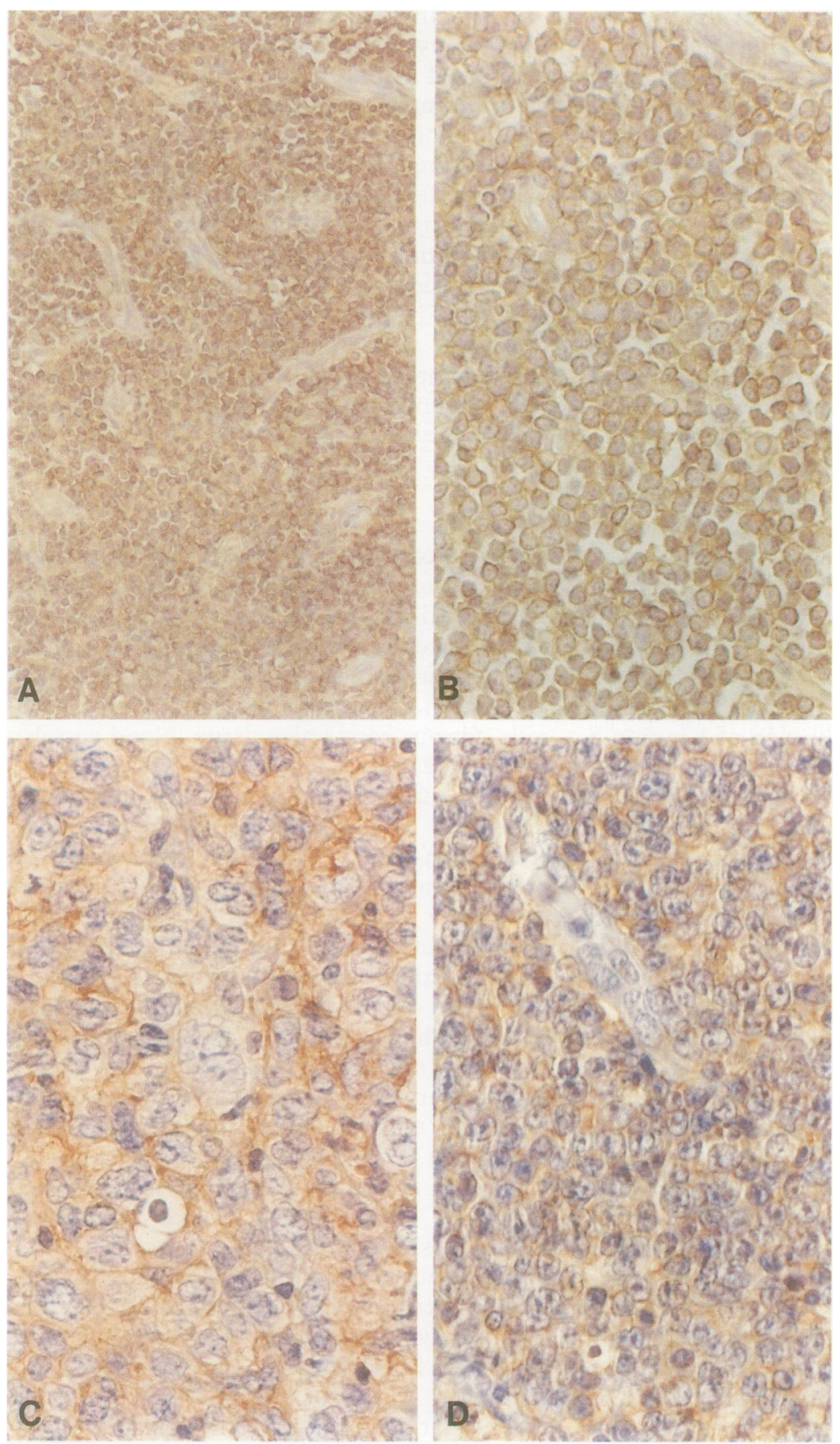

Figure 2 Paraffin wax sections stained with Campath-1G. (A) Low power view of $B$ lymphocytic lymphoma showing staining of the neoplastic cells. Small vessels are unstained. (B) High power view of $B$ cell lymphocytic lymphoma. (C) Large cell anaplastic lymphoma cells showing membrane staining. (D) Adult T cell leukaemiallymphoma cells showing staining. The cells of small vessels are unstained. Avidin-biotin complex immunoperoxidase technique with haematoxylin counterstain was used for all sections. more or less equal intensity. Of the high grade B cell NHLs stained with Campath-1G, 11 out of 16 cases were positive (fig 2C) and two further cases gave equivocal results (table 2). Five out of $10 \mathrm{~T}$ cell NHLs tested stained positively with Campath-1G (fig 2D).

\section{Discussion}

Non-neoplastic human lymphoid tissue displayed strong membrane staining on mantle zone and paracortical small lymphocytes, while weaker membrane staining was seen on follicle centre cells. This difference was present in all cases and is presumably caused by a variation in CDw52 expression.

All cases of low grade B cell NHL expressed the CDw52 antigen. Staining of high grade $B$ cell NHL and of T cell NHL was more variable. All five cases of $B$ cell lymphoblastic lymphoma tested were positive, which might be expected, given the known expression of CDw52 on B cell acute lymphoblastic leukaemia cells. ${ }^{2}$ Cases of B cell immunoblastic and large cell anaplastic lymphomas varied from positive to negative, suggesting that CDw52 antigen expression is lost in some high grade B cell NHLs. Eight out of $15 \mathrm{~T}$ cell NHLs stained with the Campath-1 antibodies. The negative cases included mycosis fungoides and high grade $\mathrm{T}$ cell NHL.

As expected, the immunohistochemical staining pattern obtained with Campath-1H and Campath-1G appeared almost identical. One case of large cell anaplastic NHL that was negative with Campath-1H was, however, positive with Campath-1G; this may have been related to the storage time of that particular sample in liquid nitrogen (four years). The failure of biotinylated or fluorescein labelled Campath-1H to stain paraffin wax sections cannot be due to the binding sites not recognising the CDw52 antigen, as the hypervariable regions are the same as in the Campath-1G antibody. The failure of staining may have been due to the conjugates causing steric hindrance at the binding sites. Support for this hypothesis comes from the abolition of staining, observed in cryostat sections, with the higher level of biotinylation of Campath$1 \mathrm{H}$.

Extrapolation of the likelihood of particular subtypes of NHL responding to treatment with Campath-1H from the immunohistochemical data is obviously somewhat uncertain. In vivo other factors will be relevant in determining the extent of Campath- $1 \mathrm{H}$ binding to NHL cell membranes-for example, the plasma concentrations of Campath-1H and the relative vascularity of different NHL subtypes. Whether Campath-1 binding then leads to cell lysis could also depend on the availability of complement and of effector cells such as macrophages and natural killer cells within the NHL tumour masses. Those considerations apart, it is suggested, on the strength of the immunohistochemical data presented here, that patients being considered 
Table 2 Immunohistochemical staining of paraffin wax sections with Campath-1G by non-Hodgkin's lymphoma subtype

\begin{tabular}{|c|c|c|c|c|}
\hline \multirow[b]{2}{*}{ Histology } & \multicolumn{4}{|c|}{ Campath-1G staining } \\
\hline & No of cases & + & \pm & - \\
\hline \multicolumn{5}{|l|}{$\begin{array}{l}\text { B cell lineage: } \\
\text { Low grade }\end{array}$} \\
\hline Lymphocytic & 1 & 1 & 0 & 0 \\
\hline Lymphoplasmacytoid/cytic & 2 & 2 & 0 & 0 \\
\hline Centroblastic/centrocytic follicular & 3 & 3 & 0 & 0 \\
\hline \multicolumn{5}{|l|}{ High grade } \\
\hline Immunoblastic & 7 & 3 & 2 & 2 \\
\hline Large cell anaplastic & 3 & 3 & 0 & 0 \\
\hline Burkitt's lymphoma (EBV -ve) & 1 & 0 & 0 & 1 \\
\hline B lymphoblastic & 5 & 5 & 0 & 0 \\
\hline \multicolumn{5}{|l|}{$T$ cell lineage: } \\
\hline Mycosis fungoides & 4 & 2 & 2 & 0 \\
\hline Adult T leukaemia/lymphoma (HTLV1 +) & 6 & 3 & 0 & 3 \\
\hline
\end{tabular}

$+=$ strong, $\pm=$ weak, $-=$ negative
4 Xia MQ, Hale G, Lifely MR, et al. Structure of the Campath-1H antigen, a GPI-anchored glycoprotein which is an exceptionally good target for complement lysis. Biochem F 1993;292:633-40.

5 Hale G, Rye PD, Warford A, Lauder I, Brito-Babapulle A The glycosylphosphatidylinositol-anchored lymphocyte antigen CDw52 is associated with the epididymal matuantigen CDw52 is associated with the epididymal maturation of human

6 Hale G, Bright S, Chumbley G, et al. Removal of T cell from bone marrow for transplantation: a monoclonal antilymphocyte antibody that fixes human complement. Blood 1983;62:873-82.

7 Dyer MJS, Hale G, Hayhoe FGJ, Waldmann H. Effects of CAMPATH-1 antibodies in vivo in patients with lymphoid malionancies: influence of antibody isotype. Blood 1989;73:1431-9.

8 Hale G, Swissky DM, Hayhoe FGJ, Waldmann H. Effects of monoclonal antilymphocyte antibodies in vivo in monkeys and humans. Mol Biol Med 1983;1:321-37.

9 Dyer MJS, Hale G, Marcus R, Waldmann H. Remission induction in patients with lymphoid malignancies using unconjugated CAMPATH-1 monoclonal antibodies. Leukaemia and Lymphoma 1990;2:179-93.

10 Reichmann L, Clark M, Waldmann H, Winter G Reshaping human antibodies for therapy. Nature 1988 ; 332:323-7.

11 Hale G, Dyer MJS, Clark MR, et al. Remission induction in non-Hodgkin lymphoma with reshaped human monoclonal antibody Campath-1H. Lancet 1988:ii:1394-9.

for Campath-1H treatment, with high grade B cell NHL (other than centroblastic or lymphoblastic) or T cell NHL (of any grade), should have CDw52 typing performed on tissue sections of their tumour. Currently phase 1 /early phase 2 clinical studies with Campath-1H are underway, and correlation of disease regression with retrospective CDw52 typing of lymph node biopsy specimens before treatment will shed further light on this.

We thank Dr AJ Norton for providing paraffin wax sections from the Department of Histopathology, St Bartholomew's Hospital Medical College. Campath is a trademark of the Wellcome Foundation Ltd.

1 Hale G, Hoang T, Prospero T, Watt SM, Waldmann H. Removal of $\mathrm{T}$ cells from bone marrow for transplantation: Comparison of rat monoclonal antibodies of different isotypes. Mol Biol Med 1983;1:305-19.

2 Hale G, Xia MO Tighe HP, Dyer MJS, Waldmann $\mathrm{H}$ The CAMPATH antigen (CDw52). Tissue Antigens 1990;35:1-10

3 Xia MQ, Tone M, Packman L, Hale G, Waldmann H Characterization of the CAMPATH-1 (CDw52) antigen: biochemical analysis and CDNA cloning reveal an unusually small peptide backbone. Eur $\mathcal{f}$ Immunol 1991;21:1677-84
12 Page MJ, Sydenham MA. High level expression of the humanised monoclonal antibody CAMPATH-1H in humanised monoclonal antibody CAMPATH-1H in 64-8.

13 Cobbold SP, Rebello PRUB, Davis HFS, Friend P, Clark MR. A simple method for measuring patient antiglobulin responses against isotypic or idiotypic determinants. f Immunol Methods 1990;127:19-24.

14 Stansfeld AG, Diebold J, Noel H, et al. Updated Kie classification for lymphomas. Lancet 1988;i:292-3.

15 Norton AJ, Isaacson PG. Lymphoma phenotyping in formalin fixed and paraffin wax-embedded tissues. I. Range of antibodies and staining patterns. Histopathology Range of antibodies formalin-fixed and paraffin wax-embedded tissues. II Histopathology 1989;14:557-79.

17 Ishii Y, Takami T, Yuasa H, Takei T, Kikuchi K. Two distinct antigen systems in human B lymphocytes: identification of cell surface and intracellular antigens usin monoclonal antibodies. Clin Exp Immunol 1984;58: 183-92.

18 Poppema S, Hollema H, Visser L, Vos H. Monoclonal antibodies (MT1, MT2, MB1, MB2, MB3) reactive with leukocyte subsets in parafin-embedded tissue with leukocyte subsets in paraffin-e

19 Smith SH, Brown MH, Rowe D, Callard RE, Beverley PCL. Functional subsets of human helper-inducer cells defined by a new monoclonal antibody, UCHL1. Immunology 1986;58:63-70.

20 Hsu S-M, Raine L, Fauger H. Use of avidin-biotin-peroxidase complex $(\mathrm{ABC})$ in immunoperoxidase techniques. f Histochem Cytochem 1981;29:577-80.
16 Norton AJ, Isaacson PG. Lymphoma phenotyping in Profiles of reactivity in the various tumour types. 